\title{
Clonal analysis of Haemophilus influenzae type $b$ isolates in the United Kingdom
}

\author{
GILLIAN URWIN, J. M. MUSSER* and MEI FANG YUAN
}

Department of Medical Microbiology, The London Hospital Medical College, Turner Street, London E1 $2 A D$ and

* Department of Pathology, Baylor College of Medicine, One Baylor Plaza, Houston, Texas 77030, USA

\begin{abstract}
Summary. Strains of Haemophilus influenzae type b were collected as part of an epidemiological study of bacterial meningitis in the North East Thames Region (NETR) of England. Subclones of $H$. influenzae were identified by outer-membrane protein typing and multilocus enzyme electrophoresis. These were compared with subclones of $H$. influenzae type $b$ isolated from elsewhere in the UK. The subclone ET 12.5/OMP $3 \mathrm{~L}$ was identified in $68 \%$ of isolates from cases of meningitis from the NETR. In the isolates from elsewhere in the UK, this subclone was identified in $79 \%$ of sterile-site isolates and $91 \%$ of isolates from non-sterile sites. This subclone predominated in patients of different ages and from different ethnic groups, which suggests that non-Caucasians are infected with the subclone predominating locally. Since ET 12.5/OMP 3L subclone is the most abundant strain isolated in virtually all other Western European countries, these results provide additional evidence that the genetic diversity in the $H$. influenzae type b population in Europe is relatively restricted.
\end{abstract}

\section{Introduction}

Haemophilus influenzae type $\mathrm{b}(\mathrm{Hib})$ is responsible for $95 \%$ of invasive disease caused by $H$. influenzae. Infections due to Hib are most common in childhood and two-thirds of cases present as meningitis. Before the widespread introduction of Hib vaccination in the UK in October 1992, the incidence of Hib disease was estimated at 26-34 cases $/ 100000$ children under the age of 5 years. ${ }^{1,2}$

Analysis of outer-membrane protein (OMP) profiles by SDS-PAGE has been used previously to form a $\mathrm{Hib}$ subtyping system. This typing scheme distinguishes 21 subtypes of Hib. ${ }^{3,4}$ Further discrimination amongst Hib isolates has been accomplished with multilocus enzyme electrophoresis. ${ }^{5}$ On the basis of variation in electrophoretic mobilities of 17 metabolic enzymes, 182 electrophoretic types (ETs) of Hib have been identified. ${ }^{6}$ This technique has demonstrated that the population structure of Hib is basically clonal. ${ }^{7,8}$ There are striking differences in the clones (determined by ET) and subclones (determined by ET and OMP subtype) predominating in the USA, Western Europe and elsewhere ${ }^{4,9}$ For example, in Europe, most strains are subclone ET 12.5/OMP 3L whereas in the USA there are several abundant subclones, including ET 1.9/OMP 1H, ET 12.5/OMP 3L and others. ${ }^{5.6}$

Received 21 Oct. 1994; revised version accepted 12 Dec. 1994.
In this study, the OMP subtypes and multilocus enzyme genotypes of Hib isolates collected in 1991 and 1992 as part of an epidemiological survey of bacterial meningitis in the North East Thames Region (NETR) of the UK were determined. The distribution of subclones was compared with that of type b isolates collected from other regions of the UK during the first 3 months of 1991 as part of a survey of the antimicrobial resistance of $H$. influenzae. ${ }^{10}$

\section{Materials and methods}

\section{Bacterial isolates}

NETR isolates. Consultant microbiologists in the NETR identified patients with primary bacterial meningitis and forwarded case details, ethnicity data and isolates to the London Hospital Medical College. During 1991 and 1992, H. influenzae caused 121 cases of meningitis, of which $114(94 \%)$ were type b. Seventy-three $(60 \%)$ isolates were available for analysis and these constituted the NETR samples.

Other UK isolates. In a survey of antimicrobial resistance, clinical isolates of all types of $H$. influenzae were collected during the first 3 months of 1991 by 23 laboratories throughout the UK $;^{10} 41 \mathrm{Hib}$ isolates were identified which had been obtained from the following sites: blood (13), CSF (14), synovial fluid (1), sputum (7), ears (2), eyes (3) and not stated (1). 


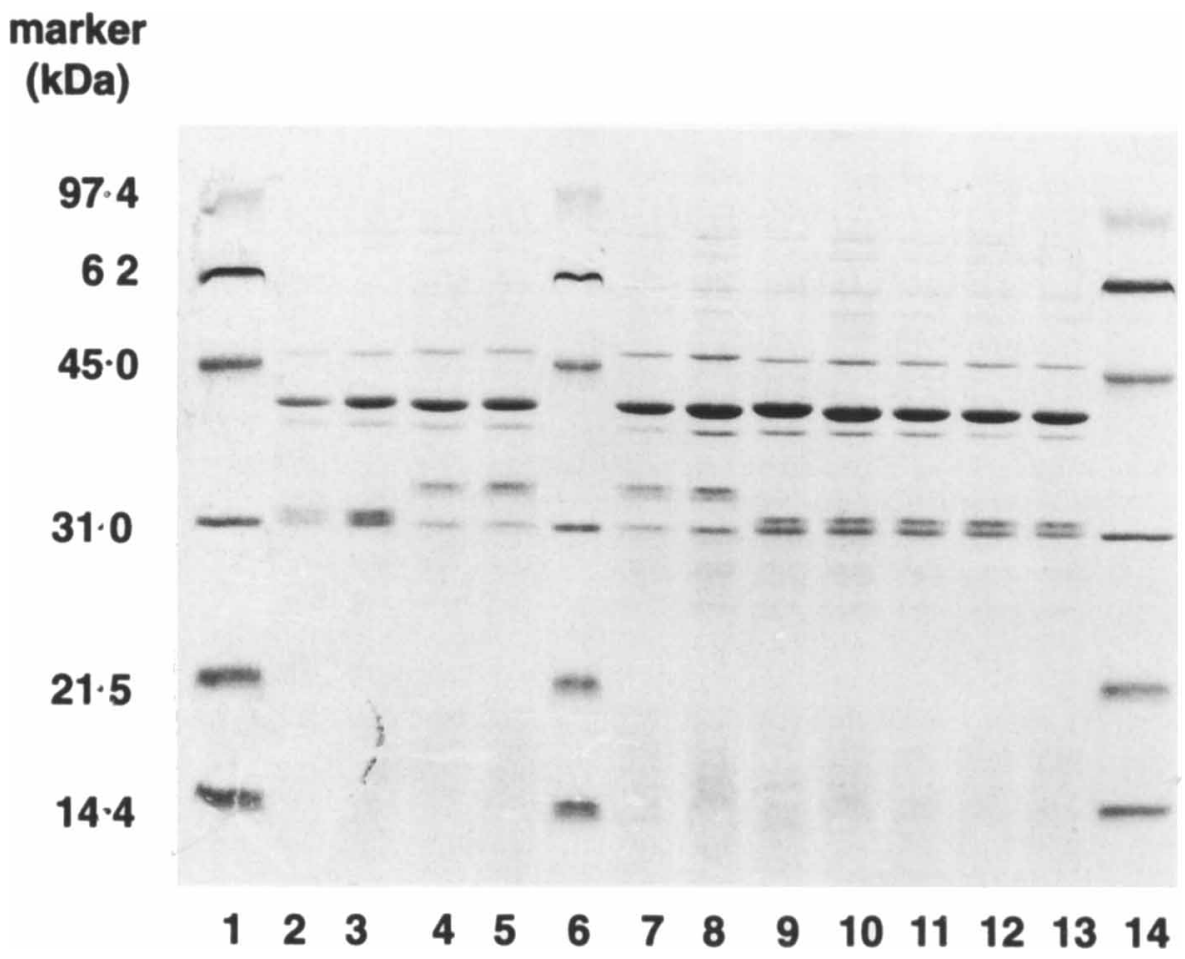

Figure. SDS-PAGE gel showing Hib OMP subtypes of control strains and seven meningitis isolates. Lanes 1, 6, 14: molecular size markers; 2, 3: controls, OMP subtype $3 \mathrm{~L} ; \mathbf{4}, \mathbf{5}$ : controls, OMP subtype $1 \mathrm{H} ; \mathbf{7}, \mathbf{8}$ : meningitis isolates of subtype $1 \mathrm{H} ; \mathbf{9 - 1 3}$ meningitis isolates of subtype 3L.

All strains were confirmed as $H$. influenzae by XVdisk satellitism and a negative result in the porphyrinproduction test. ${ }^{11}$ The capsular type was determined by agglutination with $H$. influenzae type b-specific antiserum (Wellcome).

\section{Statistical analysis}

All tests of significance were performed with Epi Info 5.01 (Centers for Disease Control and Prevention, Atlanta, GA 30333, USA). The $\chi^{2}$ test and Fisher's exact test were used as appropriate for statistical analysis.

OMP subtyping and multilocus enzyme electrophoresis

OMP subtyping was performed by SDS-PAGE of outer-membrane preparations of $H$. influenzae prepared as described by Stull et al. ${ }^{12}$ Cultures were grown to mid-log phase in brain heart infusion broth supplemented with Fildes's extract $5 \%$. Cells were harvested by centrifugation at $3000 \mathrm{rpm}$ for $20 \mathrm{~min}$ and resuspended in $8 \mathrm{ml}$ of $10 \mathrm{~mm}$ Tris-acetate buffer, $\mathrm{pH} 7 \cdot 2$ containing $0.75 \mathrm{M}$ sucrose and $5 \mathrm{mM} \mathrm{MgCl}_{2}$, to which lysozyme $100 \mu \mathrm{g}$, DNAase $800 \mu \mathrm{g}$ and RNAase $800 \mu \mathrm{g}$ (all from Sigma) were added. Sonication $(4 \times 15 \mathrm{~s})$ was used to disrupt the cells, with cooling on ice between bursts of sonication. The sonicate was centrifuged at $150000 \mathrm{~g}$ for $1 \mathrm{~h}$ at $4^{\circ} \mathrm{C}$ and the resulting pellet was

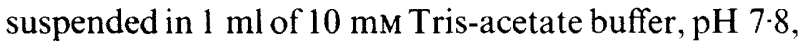
and $1 \mathrm{ml}$ of Triton X-100 $4 \% \mathrm{v} / \mathrm{v}$ in the same buffer. After incubation at room temperature for $20 \mathrm{~min}$, centrifugation and resuspension of the pellet was repeated, with a $2 \% \mathrm{v} / \mathrm{v}$ solution of Triton $\mathrm{X}-100$. The detergent-insoluble membrane fractions were heated to $100^{\circ} \mathrm{C}$ in $\operatorname{SDS} 1 \% \mathrm{w} / \mathrm{v}$ for $5 \mathrm{~min}$ before electrophoresis.

Electrophoresis of the outer-membrane preparations was as described by Barenkamp et al.,$^{3}$ with a modified Laemmli gel system based on the procedure of Lugtenberg et al. ${ }^{13}$ Stacking and running gels contained acrylamide $6 \%$ and $14 \% \mathrm{w} / \mathrm{v}$, respectively. OMP subtypes were identified on the basis of the patterns produced by the major protein bands, ${ }^{3}$ and were confirmed by comparison with Barenkamp reference strains provided by $\mathrm{Dr} \mathrm{Z}$. Jordens (Public Health Laboratory, John Radcliffe Hospital, Oxford) (figure). The OMP subtypes of a selection of subtype $1 \mathrm{H}$ strains was confirmed by Dr J. Ward (Department of Paediatrics, UCLA Center for Vaccine Research, Harbor-UCLA Medical Center, 1000 West Carson Avenue, Torrance CA 90509, USA).

Electrophoretic types were determined by analysis of allelic variation in 17 chromosomally determined metabolic enzymes. ${ }^{5}$ Electromorphs of each enzyme correspond with alleles on the chromosome. Distinctive combinations represent multilocus genotypes and are designated as electrophoretic types.

Isolates were designated into subclones on the basis of their ET/OMP subtype and clones on the basis of their ET alone, as has been described previously. ${ }^{5.6}$ 


\section{Results}

\section{NETR isolates}

Amongst the 73 isolates from cases of meningitis, the outer-membrane protein subtype $3 \mathrm{~L}$ was the most common, found in $57(78 \%)$ of cases (table I). The subclone ET 12.5/OMP 3L predominated, accounting for $50(68 \%)$ of the isolates. The next most common subclone from cases of meningitis was ET 1.9/OMP $1 \mathrm{H}(12 \%)$.

Sixty-eight $(96 \%)$ of 71 isolates where age was

Table I. Multilocus enzyme genotypes (electrophoretic types, ET) and OMP subtypes of $H$. influenzae type $b$ isolates from cases of meningitis in the North East Thames Region

\begin{tabular}{lllllllr} 
& \multicolumn{6}{c}{ Number (\%) of isolates of OMP subtype } \\
\cline { 2 - 8 } & $1 \mathrm{H}$ & $1 \mathrm{~L}$ & $2 \mathrm{~L}$ & $3 \mathrm{~L}$ & $6 \mathrm{U}$ & Other & Total \\
\hline 1.9 & $9(12)$ & 0 & 0 & 0 & 0 & 0 & $9(12)$ \\
12.5 & 0 & $1(1)$ & 0 & $50(68)$ & 0 & 0 & $51(69)$ \\
12.8 & $2(3)$ & 0 & $1(1)$ & $4(7)$ & 0 & 0 & $7(11)$ \\
$12.5 \mathrm{v}^{*}$ & 0 & 0 & 0 & $1(1)$ & 0 & 0 & $1(1)$ \\
$12.51 \dagger$ & 0 & 0 & 0 & $1(1)$ & 0 & 0 & $1(1)$ \\
$12 \mathrm{v}^{*}$ & 0 & 0 & 0 & $1(1)$ & 0 & $1(1)$ & $1(2)$ \\
25.6 & 0 & 0 & 0 & 0 & $2(3)$ & 0 & $2(3)$ \\
Total & $11(15)$ & $1(1)$ & $1(1)$ & $57(78)$ & $2(3)$ & $1(1)$ & $73(99)$ \\
\end{tabular}

Percentages do not add up to 100 due to rounding.

$* \mathrm{v}$, variant isolate, each a distinct multilocus genotype.

$\dagger$ Multilocus enzyme genotype similar to, but distinct from, ET 12.5 .

Table II. Distribution of subclones of Hib isolates from cases of meningitis in NETR according to age of patient

\begin{tabular}{lccccc}
\hline \multirow{2}{*}{$\begin{array}{l}\text { Age } \\
\text { group } \\
\text { (years) }\end{array}$} & \multicolumn{4}{c}{ Number of isolates of subclone (ET/OMP) } \\
\cline { 2 - 6 } & $12.5 / 3 \mathrm{~L}$ & $12.8 / 3 \mathrm{~L}$ & $1.9 / 1 \mathrm{H}$ & Other & Total \\
\hline$<1$ & 20 & 2 & 5 & 5 & 32 \\
$1-4$ & 25 & 2 & 4 & 5 & 36 \\
$5-19$ & 1 & 0 & 0 & 0 & 1 \\
$20-39$ & 0 & 0 & 0 & 0 & 0 \\
$40-59$ & 1 & 0 & 0 & 0 & 1 \\
$60+$ & 1 & 0 & 0 & 0 & 1 \\
Total & 48 & 4 & 9 & 10 & $78^{*}$ \\
\hline
\end{tabular}

* Details of age unavailable in two cases.

Table III. Distribution of subclones of isolates from cases of $\mathrm{Hib}$ meningitis according to ethnicity of patients from NETR

\begin{tabular}{lccccc}
\hline & \multicolumn{5}{c}{ Number of isolates of subclone (ET/OMP) } \\
\cline { 2 - 6 } $\begin{array}{l}\text { Ethnic } \\
\text { group }\end{array}$ & $12.5 / 3 \mathrm{~L}$ & $12.8 / 3 \mathrm{~L}$ & $1.9 / 1 \mathrm{H}$ & Other & Total \\
\hline Caucasian & 39 & 4 & 7 & 8 & 58 \\
Asian & 4 & 0 & 2 & 1 & 7 \\
Black & 2 & 0 & 0 & 0 & 2 \\
Other & 2 & 0 & 0 & 0 & 2 \\
Unknown & 2 & 0 & 0 & 2 & 4 \\
Total & 49 & 4 & 9 & 11 & 73 \\
\end{tabular}

Table IV. Analysis of subclones of isolates collected from throughout the UK according to culture site

\begin{tabular}{|c|c|c|c|c|c|}
\hline \multirow{2}{*}{ Site } & \multicolumn{5}{|c|}{ Number of isolates of subclone (ET/OMP) } \\
\hline & $12.5 / 3 \mathrm{~L}$ & $12.8 / 3 \mathrm{~L}$ & $12.7 / 3 \mathrm{~L}$ & Other & Total \\
\hline $\mathrm{CSF}$ & 11 & 0 & 1 & $2^{*}$ & 14 \\
\hline Blood & 11 & 1 & 1 & 0 & 13 \\
\hline Joint & 0 & 0 & 0 & $1 \dagger$ & 1 \\
\hline Sputum & 5 & 0 & 1 & $1+$ & 7 \\
\hline Ear & 2 & 0 & 0 & 0 & 2 \\
\hline Eye & 3 & 0 & 0 & 0 & 3 \\
\hline Total & 32 & 1 & 3 & 4 & 40 \\
\hline
\end{tabular}

* Subclone $12.8 / 11 \mathrm{~L}, 12.6 / 3 \mathrm{~L}$.

$\dagger$ Subclone 12.5/14L.

‡ ET unknown, OMP 3L.

Site unknown in one case.

Table V. Analysis of Hib isolates from 23 laboratories in the UK according to subclone and age of patient

\begin{tabular}{lcccc}
\hline \multirow{2}{*}{ Age in years } & \multicolumn{5}{c}{ Number of isolates of subclone (ET/OMP) } \\
\cline { 2 - 5 } & $3 \mathrm{~L} / 12.5$ & $3 \mathrm{~L} / 12.7$ & Other & Total \\
\hline$<5$ & 20 & 1 & 3 & 24 \\
$5-19$ & 7 & 0 & 1 & 8 \\
$20-29$ & 1 & 1 & 0 & 2 \\
$30-39$ & 0 & 0 & 0 & 0 \\
$40+$ & 1 & 1 & 1 & 3 \\
Total & 29 & 3 & 5 & 37
\end{tabular}

Details of age unavailable in four cases.

known were from children under the age of 5 years (table II). The subclone ET 12.5/OMP $3 \mathrm{~L}$ caused 45 cases $(63 \%)$ of disease in this age group and nine $(13 \%)$ of the children under 5 years of age were infected with subclone ET 1.9/OMP $1 \mathrm{H}$. The three adult cases were all infected with subclone ET 12.5/ OMP 3L.

There were 11 cases in non-Caucasians (table III). Subclone ET 12.5/OMP 3L accounted for eight of these cases. There was no significant difference between the proportion of isolates of this subclone $(\mathrm{p}=1)$ or ET 1.9/OMP $1 \mathrm{H}(\mathrm{p}=0.6)$ in Caucasians and non-Caucasians.

\section{Other UK isolates}

Thirty-two $(78 \%)$ of the isolates belonged to subclone ET 12.5/OMP 3L. Table IV shows a comparison of subclones found from normally sterile sites (CSF, blood; joint) with those from non-sterile sites (sputum, ears, eyes). There were 28 isolates from normally sterile sites and $22(79 \%)$ were the common subclone ET 12.5/OMP 3L. Ten (91\%) of 12 isolates from nonsterile sites were of this subclone $(p=0 \cdot 2$, comparing the predominant subclone found in normally sterile and non-sterile sites). There were no isolates of subclone ET 1.9/OMP $1 \mathrm{H}$ in this collection of isolates.

Table $\mathrm{V}$ shows the subclones predominating in 
different age groups. Subclone ET 12.5/OMP 3L was isolated from $20(83 \%)$ of the patients $<5$ years, and $9(69 \%)$ of the patients $>5$ years old.

\section{Discussion}

Analysis of the population structure of capsulate $H$. influenzae has shown the species to be clonal, with 182 different ETs found amongst type b isolates. Despite the large number of clones identified, nine clones accounted for $81 \%$ of cases of invasive disease worldwide."

Musser et $a l .{ }^{6}$ identified striking geographical variation in the abundance of clones and subclones. In the USA, $41 \%$ of isolates were ET 1.9 and virtually all were of OMP subtype $1 \mathrm{H}$. In Iceland, $82 \%$ of isolates were of this electrophoretic type but, in contrast, the majority were of OMP subtype 2L. In Western Europe, $56 \%$ of isolates belonged to ET 12.5, and ET 1.9 accounted for a further $14 \%$ of cases. Almost all European isolates of ET 1.9 were OMP subtype $1 \mathrm{~L}$ or $2 \mathrm{~L} .{ }^{6}$ Others have demonstrated the predominance of subclone ET 12.5/OMP 3L in Western Europe. Van Alphen et al. ${ }^{14}$ identified $75 \%$ of isolates from patients in the Netherlands with meningitis to be OMP subtype 1 (Barenkamp OMP subtype 3L). In Wales, Howard et al. ${ }^{15}$ found $78 \%$ of isolates from all invasive $\mathrm{Hib}$ disease to be ET 12.5. In contrast, $58(95 \%)$ of 61 isolates of Hib from Pakistani children with lower respiratory tract infection belonged to a subclone rarely seen in the USA or Europe, ET 141/OMP 6U. ${ }^{16}$

Although there are geographical differences in the clones and subclones in different continents, there is little evidence to suggest differences in pathogenicity between the clones that cause the majority of invasive Hib disease. In a study from Finland, Hib of OMP

\section{References}

1. Nazareth B. Slack MPE. Howard AJ, Wright PA, Begg NT. A survey of invasive Haemophilus influenzae infections. Communicable Disease Report (CDR Rev) 1992: 2: R13-16.

2. Tudor-Williams G. Frankland J. Isaacs D et al. Haemophilus influenzae type b disease in the Oxford region. Arch Dis Child 1989; 64: 517-519.

3. Barenkamp SJ, Munson RS. Granoff DM. Subtyping isolates of Haemophilus influenzae type $b$ by outer-membrane protein profiles. $J$ Infect Dis 1981 ; 143: 668-676.

4. van Alphen L. Riemens T, Poolman J, Hopman C. Zanen HC. Homogeneity of cell envelope protein subtypes, lipopolysaccharide serotypes, and biotypes among Haemophilus influenza' type $b$ from patients with meningitis in The Netherlands. $J$ Infect Dis 1983: $148: 75-81$.

5. Musser JM. Granoff DM. Pattison PE. Selander RK. A population genetic framework for the study of invasive diseases caused by serotype b strains of Haemophilus influenzae. Proc Natl Acad Sci USA 1985; 82: 5078-5082.

6. Musser JM. Kroll JS. Granoff DM et al. Global genetic structure and molecular epidemiology of encapsulated Haemophilus influenzae. Rev Infect Dis 1990; 12: 75-111.

7. Musser JM, Kroll SJ. Moxon ER, Selander RK. Evolutionary genetics of encapsulated strains of Haemophilus influenzae. Proc Nall Acad Sci USA 1988; 85: 7758-7762. subtype $1 \mathrm{c}$ caused proportionally more meningitis and less epiglottitis than strains of OMP subtype 1 (typing nomenclature of van Alphen et al.). ${ }^{4,17}$ Barenkamp et al. ${ }^{18}$ described the OMP subtype $1 \mathrm{H}$ as being more transmissible and possibly more virulent than other OMP subtypes within a day-care setting. One particular subclone (ET 21.6/OMP 13L) has been associated with respiratory-tract carriage. ${ }^{9,19}$

Our data demonstrate that, in the UK, subclone ET 12.5/OMP 3L predominates, as in other parts of Western Europe. There was no difference in the distribution of subclones isolated from Caucasians and non-Caucasians in the NETR study, which suggests that non-Caucasians are infected with the subclone predominating locally.

In the group of isolates from elsewhere in the UK, the subclone predominating in normally sterile body sites (ET 12.5/OMP 3L) was the same as that found in isolates from non-sterile sites. Subclone ET 1.9/OMP $1 \mathrm{H}$ appeared only in NETR isolates from cases of meningitis and was not found in the other UK samples. This subclone has not been identified in any other European country but is well documented in the USA.

Overall, the predominant subclone causing meningitis was the same as that causing other forms of $\mathrm{Hib}$ disease. This subclone is the most abundant strain of Hib isolated in virtually all other Western European countries, providing additional evidence that the genetic diversity of the Hib population in Europe is relatively restricted.

We are grateful to all the consultant microbiologists and their staff in the NETR for their help with the meningitis study. We thank Dr M. Powell for allowing us to study the isolates collected during the survey of antimicrobial resistance, Dr N. Banatvala for review of the manuscript and Dr J. Ward for confirming the OMP subtypes of a selection of isolates. This work was supported by a grant from the Wolfson Foundation.

8. Musser JM, Kapur V. Molecular population genetics of Haemophilus influenzae. In: Ellis RW, Granoff DM (eds) Development and clinical uses of Haemophilus b conjugate vaccines. Infections disease and therapy, vol 11. New York, Marcel Dekker. 1994: 179-206.

9. Hampton CM, Barenkamp SJ, Granoff DM. Comparison of outer membrane protein subtypes of Haemophilus influenzae type $\mathrm{b}$ isolates from healthy children in the general population and from diseased patients. J Clin Microbiol $1983 ; 18$ : $596-600$.

10. Powell M, Fah YS, Seymour A, Yuan M, Williams JD. Antimicrobial resistance in Haemophilus influenzae from England and Scotland in 1991. J Antimicrob Chemother 1992; 29: $547-55$.

11. Kilian M. A taxonomic study of the genus Haemophilus, with the proposal for a new species. J Gen Microbiol 1976; 93 : $9-62$.

12. Stull TL, Mack K, Haas JE, Smit J, Smith AL. A comparison of techniques for isolation of the outer membrane proteins of Haemophilus influenzae type b. Anal Biochem 1985; 150: $471-80$

13. Lugtenberg B, Meijers J, Peters R, van der Hoek P, van Alphen L. Electrophoretic resolution of the 'major outer membrane protein' of Escherichia coli K12 into four bands. FEBS Lett 1975; 58 : 254-58.

14. van Alphen L, Geelen L, Jónsdóttir K, Takala AK, Kãyty H, Zanen HC. Distinct geographic distribution of subtypes of 
Haemophilus influenzae type b in Western Europe. $J$ Infect Dis 1987; 156: 216-218.

15. Howard AJ, Dunkin KT, Musser JM, Palmer SR. Epidemiology of Haemophilus influenzae type $\mathrm{b}$ invasive disease in Wales. BMJ 1991; 303: 441-445.

16. Weinberg GA, Ghafoor A, Ishaq Z et al. Clonal analysis of Haemophilus influenzae isolated from children from Pakistan with lower respiratory tract infections. $J$ Infect Dis $1989 ; 160: 634-643$.

17. Takala AK, van Alphen L, Eskola J, Palmgren J, Bol P, Mäkelä PH. Haemophilus influenzae type b strains of outer mem- brane subtypes 1 and 1c cause different types of invasive disease. Lancet 1987; 2: 647-650.

18. Barenkamp SJ, Granoff DM, Munson RS. Outer-membrane protein subtypes of Haemophilus influenzae type b and spread of disease in day-care centers. J Infect Dis 1981; 144: $210-217$.

19. van Alphen L, Bol P, Kok MLJ, Geelen-van den Broek L. Differences in subtype distribution of Haemophilus influenzae type $\mathrm{b}$ from carriers in the general population and patients with meningitis. J Med Microbiol 1991; 34: 313-316. 